\title{
A study of the micro-hole geometry evolution on glass by abrasive air-jet micromachining
}

\author{
Huaizhong $\mathrm{Li}^{1 *}$, Jun Wang², Ngaiming Kwok², Thai Nguyen³ ${ }^{3}$ Guan Heng Yeoh² \\ ${ }^{1}$ Griffith School of Engineering, Griffith University, QLD 4222, Australia \\ ${ }^{2}$ School of Mechanical and Manufacturing Engineering, UNSW Australia, Sydney, NSW 2052,
} Australia

${ }^{3}$ School of Aerospace, Mechanical and Mechatronic Engineering, The University of Sydney, Sydney, Australia

\section{Corresponding Author:}

Dr Huaizhong Li

Griffith School of Engineering, Gold Coast campus, Griffith University, QLD 4222, Australia. E-mail: lihuaizhong@gmail.com; h.li@griffith.edu.au.

Telephone: +61 (7) 5552 8252; Facsimile: +61 (7) 55528062

\begin{abstract}
Abrasive air-jet (AAJ) micromachining has become an attractive technology for the fabrication of micro-structures on a wide range of engineering materials. However, problems specific to effective mould construction still remain challenging. This paper presents a study on the evolution of micro and blind holes on glass during abrasive air-jet machining. Experiments were conducted under different practical settings of air pressure, particle mass flow rate and drilling time. A 3D laser measurement microscope was used to characterise the machined hole profiles. It was found that there
\end{abstract}


was a clear evolution of the profiles of the hole bottom surfaces. Three types of hole surface contours, i.e., convex, flat, and concave (reverse bell-shaped), were obtained within the operating range used, in which the first two types have rarely been reported in literature. The profile variation took place along with the setting parameters of particle flow rate and air pressure, which indicated that the particles distribution density across the cross section of a cylindrical nozzle also varied with the setting parameters. At a low flow rate, the hole bottom was formed with a convex shape, which might be attributed to the fact that the distribution of particles at the nozzle centre was less than that around the brim. As the particle flow rate increased, the bottom surface evolved from convex to flat or even concave. With a proper setting, AAJ can therefore be used to fabricate a micro hole with a desired bottom surface profile. The variation of abrasive particle distribution in the jet in the AAJ micromachining might be attributed to the flow bounce back and stagnation effects when the jet impacts on a target workpiece.

Keywords: micromachining; erosion; abrasive air-jet; difficult-to-machine; gas-solid; hole-drilling.

\section{Introduction}

Current techniques for micromachining of difficult-to-machine materials, such as laser machining and electrical discharge machining (EDM), essentially require large energy generated from complex heat-sourced machines to thermally destroy and remove unwanted materials. Owing to its distinct features of thermal damage free and flexibility in machine setup, abrasive air-jet (AAJ) machining, also known as abrasive jet micromachining (AJM), has become an energy-efficient and attractive method for micromachining components made from advanced but difficult-to-machine materials, 
including glass, ceramics, quartz and silicon which are increasingly selected for constructing modern micro-featured devices, such as electronic components and micro-fluidic channels [1,2].

In AJM, materials are eroded by an air jet with abrasive particles. An AJM system typically consists of a high-pressure air supplier, a mixing chamber where abrasives are mixed with air, a nozzle, and a positioning system for the nozzle or cutting head. The abrasive particles are accelerated to a high velocity by applying pressurized air in a fine nozzle, and the nozzle moves relative to the work substrate in order to produce the desired structure [3]. By transferring the momentum from the pressurized air onto the abrasive particles, the AAJ is capable of eroding the target material to generate the required part features by means of micro-plastic deformation and/or brittle fracture through the impact of the high velocity abrasives $[3,4]$. For particular hard and brittle materials, brittle fracture becomes dominant. In this fracture mode, upon the impact of a particle, a fragmentation zone that consists of a complex network of cracks with random sizes and locations is formed, and localized cracks are generated at the work surface due to the impact force of the abrasive particles. The continuous motion of particle penetrating into the zone causes a propagation of cracks. Fragments loosen from the cracks can be immediately generated upon that impact or by the impact of other following particles in the vicinity of the generated fragmentation zone. The loose fragments are finally taken away from the zone by the air jet flow, which causes the removal of the target material $[1,4]$.

The features formed on the target material, such as groove width and depth, kerf geometry, hole shapes, surface integrity, etc., are a result of a combination of multiple impact of a number of particles through an abrasive-laden air jet ejected from a nozzle. It is noted that not all the particles within an air jet are evenly distributed and have the same velocity. This in fact depends on various 
process parameters, such as nozzle type and size, air pressure, particle size and flow rate related to the nozzle size, and processing time [3,5]. There have been several studies to characterize the AAJ process. However, the major parameters that govern the process in forming the profile of feature machined are controversial. Achtsnick et al. [6] in an analysis of the micro-abrasive blasting process showed that the particle dispersion depends on the nozzle type, and cylindrical nozzles generate an axis symmetrical normal distribution. Under such circumstance, it seems that a feature with flat bottom may not be obtained by a cylindrical nozzle, but by a line shaped Laval nozzle where the particle flow can be spread evenly on the target surface. In another separate study conducted by Balasubramaniam et al. [7], it was found that the machined surfaces are of reverse-bell shape. They therefore believed that the abrasive concentration was highest at the centre line of the jet and reduced as approaching to the periphery. Ghobeity et al. [8] on the other hand, pointed out the importance of particle sizes, which are varied across the nozzle section, and this distribution can significantly influence the depth and shape of resultant profiles. A computer simulation reported in [9] illustrates that there are collisions between incoming and rebounding particles. Burzynski and Papini [10] suggested that, apart from the non-uniform incident particle spatial distribution and velocity, there is also a variation in particle spacing along the jet axis. In a study to understand the microscopic erosion mechanisms of monocrystalline silicon under the impacts of microsolid particles, Li et al. [11] found that the majority of the particles bounced away from the target surface without sliding or rolling during the impact. An analytical approach for predicting the surface profile of micro-channels machined using air driven abrasive jets for brittle materials had been proposed in [12], which was mainly for masked erosion of glass by powder blasting. A method to estimate the profiles of holes and micro-channels fabricated in glass using a jet of abrasive slurry was presented in [13]. Jafar et al. [14,15] studied the effects of particle size, kinetic energy, and attack angles on the rough micro-channels using AJM. They found that in order to decrease the AAJ machined surface 
roughness of the fabricated channels, it is effective to do post-blasting using abrasive jet with low kinetic energy.

In spite of the research efforts in recent years, the effects of different parameters on the shape of the resultant surface using AJM are not widely investigated. Nouraei et al. [16] compared abrasive slurry jet micro-machining (ASJM) with abrasive air jet micro-machining, and confirmed that the erosion mechanisms in ASJM and AJM were similar with a borosilicate glass. They found that the holes machined using ASJM were with relatively steep sidewalls and flat bottoms while those machined using masked AJM were more "V" shaped. Wang et al. [17] reported that during the microhole formation on brittle glasses by an abrasive slurry jet, the hole cross section is characterized by a "W" shape, which can be mainly attributed to the fluid diversion characteristics when a jet impacts a material surface. Due to the existence of a stagnation zone upon the jet impingement, the particle impact velocities and angles at the center of the jet and at the edge of the jet are different $[18,19]$. The stagnation zone can apply great drag on the abrasive particles thus decrease the erosion rate. Fan et al. [20] investigated the velocity distributions and particle behaviors of the free jet and impinging jet in and out of the nozzle for a micro abrasive water jet (MAWJ) process, and showed that a W-shaped contour is formed in the microhole machining due to a secondary erosion process caused by the expansion of the viscous jet flow along the target surface in the wall jet region. On the other hand, for the microhole formation using AJM, only reverse bell shaped or "U" shaped contours have been reported in almost all available literatures so far. In the AJM process, a stagnation zone should also exist which can vary the particle impact velocities and angles. A further examination of the micro-hole contour evolution on glass by abrasive air-jet micromachining will help to understand the mechanisms in the process which can facilitate process planning and optimization. 
This paper presents an experimental study on the micro-hole shape evolution in abrasive jet micromachining of glass. Experiments are conducted under different air pressures and abrasive mass flow rates for fabricating blind holes on the workpiece. A 3D laser scanning measurement microscope is used to characterize the machined surface profile. The influences of key process parameters, including air pressure and abrasive mass flow rate, on the surface profile evolution are analysed and discussed.

\section{Experimental Methods}

Experiments were conducted using an Airbrasive Model K Series II air jet machine as shown in Fig. 1. This machine allows the adjustment of air pressure and abrasive flow according to the experimental needs. A Roland MDX-40 two-axis motion stage with a closed chamber was used to hold and move the jet nozzle for AJM operation. A dust collector was incorporated in the Roland MDX-40 machine. The machine received user command from a control PC through an input notepad and translated it into nozzle movement. The transverse or scanning speed and the distance to move were adjustable by changing the control program code. The nozzle was a cylindrical type with an inner diameter of $0.28 \mathrm{~mm}$. The abrasive powder was aluminium oxide with a nominal diameter of $27 \mu \mathrm{m}$. An image of the abrasive particles is shown in Fig. 2. The abrasive powder was fed into the powder container of the abrasive jet machine and its flow rate was calibrated for precision supply. The workpiece material was lime glass which is commonly used to manufacture glass container, window panes, and micro-channels. The lime glass was in a dimension of $50 \mathrm{~mm} \times 50 \mathrm{~mm} \times 5 \mathrm{~mm}$.

In the experiments, a nozzle standoff distance of $0.5 \mathrm{~mm}$ and jet impact angle of 90 degrees were considered. Different abrasive flow rate, air pressure, and drilling time were used to investigate their effects on the hole evolution. Some pilot experiments were carried out to determine the parameter 
settings. The air pressures used were $0.427,0.517$, and $0.600 \mathrm{MPa}$ (or 62, 75 and $87 \mathrm{psi}$ respectively); the abrasive flow rates were $0.02,0.04,0.07$, and $0.09 \mathrm{~g} / \mathrm{s}$; and the drilling time was 7,10 , and 15 seconds. A Keyence model VK-X200K 3D laser measurement microscope was used to measure the hole profiles. This microscope uses a laser to scan across a target for non-contact surface characterization. These include surface profile, surface roughness and crater value measurements on the sample with high-resolution and high throughput. The depth, diameter and wall taper angle for each hole drilled were measured using the laser microscope.

\section{Results and Discussions}

It was observed that under different cutting parameters, the hole shapes exhibited some variations in terms of the bottom surface and the side kerf slope. Within the operating range used, three main types of hole bottom contours were obtained, as shown in Fig. 3(a-c). The cross-sectional profile curves of the bottom surfaces can be classified as convex bottom (similar to the so-called "W" shape), nearly flat bottom, and reverse bell shape bottom (or "U" shape), respectively. In addition, the kerf slope varied from steep to gradual.

The hole profile shown in Fig. 3(a), a convex bottom, was obtained under the cutting condition of an abrasive flow rate $0.02 \mathrm{~g} / \mathrm{s}$, air pressure $0.427 \mathrm{MPa}$, and drilling time $7 \mathrm{~s}$. The hole kerf angle is small, which means that the hole side wall is steep. The hole bottom surface is convex, with the centre of the hole bottom as the shallowest and the edge side as the deepest location of the hole. To form the convex bottom shape, more material was eroded towards the edge of the hole than at the centre by the impinging abrasive particles. Correspondingly, the distribution of abrasive particles in the jet under this parameter setting was not a normal distribution. Instead, more abrasive particles were concentrated at the brim of the jet. Therefore a steeper taper was formed. 
The nearly flat hole bottom shape as shown in Fig. 3(b) was fabricated by using the cutting condition of $0.600 \mathrm{MPa}$ air pressure, $0.04 \mathrm{~g} / \mathrm{s}$ abrasive flow rate, and $7 \mathrm{~s}$ drilling time. It can be seen that the hole has a shape of approximately frustum of a cone, with a larger cone top diameter than the cone bottom diameter. There exists a clear taper on the side wall of the hole. The nearly flat bottom surface indicates that the abrasive particles in the jet under this condition were evenly distributed. Under higher abrasive flow rate and air pressure, a reverse bell shape bottom surface was formed, as shown in Fig. 3(c). It was under the condition of 0.600 MPa air pressure, $0.09 \mathrm{~g} / \mathrm{s}$ abrasive flow rate, and $7 \mathrm{~s}$ drilling time. The hole profile was like the inner shape of a bowl. In this case, the particle distribution in the jet was different from the aforementioned two cases. More abrasive particles were distributed towards the centre of the jet cross-section.

It is clear that the evolution of the micro hole contours is caused by the variation of the AJM parameters. To investigate the influences of particle flow rate and air pressure, a comparison of the vertical sectional profiles of the micro-machined holes under different parameter settings is shown in Fig. 4. The cutting time was $7 \mathrm{~s}$ for all tests shown. The hole profile images in Fig. 4 from top to bottom are arranged corresponding to particle flow rates at $0.02 \mathrm{~g} / \mathrm{s}, 0.04 \mathrm{~g} / \mathrm{s}, 0.07 \mathrm{~g} / \mathrm{s}$, and $0.09 \mathrm{~g} / \mathrm{s}$ respectively. From left to right, images corresponded to air pressures at $0.427 \mathrm{MPa}, 0.517 \mathrm{MPa}$, and 0.600 MPa respectively. The hole shape evolution along with the change of abrasive flow rate and air pressure is clearly illustrated in the figure. Under low flow rate and low air pressure, the hole bottom was convex shaped, with the deepest location at the edge of the bottom and the shallowest in the centre. The side kerf angle was also small. With an increase in particle flow rate, the bottom surface evolved from convex to flat, and then to reverse bell shape. The higher abrasive flow rate also caused an increase in the hole depth. On the other hand, an increment in terms of air pressure also caused 
slight variation of the hole bottom profile in a similar way. Comparing with the profiles shown in the top row of this figure, it is observed that the degree of convexity of the resultant hole surfaces was less when the air pressure was higher, though there was still a slight convex shape existed. From the third row and the fourth row, it can be seen that the hole bottom surface evolved from near flat to slightly concave, or even to reverse bell shape with the deepest location in the centre. However, the influence of the air pressure on the hole profile is not as significant as that of the particle flow rate. From the observation, a change of particle spatial distribution might be resulted by variation of particle flow rate. A higher particle flow rate may cause more particles distributed close to the centre of the jet, while a lower particle flow rate may cause less particles distributed close to the centre.

The influence of the drilling time is illustrated in Fig. 5. From top row to bottom row, the drilling time was 7, 10, and 15 s respectively. For the left, middle, and right column, the abrasive flow rate was $0.02 \mathrm{~g} / \mathrm{s}, 0.04 \mathrm{~g} / \mathrm{s}$, and $0.09 \mathrm{~g} / \mathrm{s}$ respectively, while the air pressure was 0.427 MPa, 0.600 MPa, and 0.600 MPa respectively. From the figures of the hole profile, it can be seen that the hole surface contours are mainly correlated to particle flow rate and air pressure. Similar to the cases shown in Fig. 4, convex bottom contours were achieved under an abrasive flow rate of $0.02 \mathrm{~g} / \mathrm{s}$ and air pressure of $0.427 \mathrm{MPa}$, flat contours occurred under an abrasive flow rate of $0.04 \mathrm{~g} / \mathrm{s}$ and air pressure of $0.600 \mathrm{MPa}$, and reverse bell shapes under an abrasive flow rate of $0.09 \mathrm{~g} / \mathrm{s}$ and air pressure of 0.600 MPa. The variation of drilling time did not result in a significant change to the hole surface contour, other than a minor trend that the edge of the hole became deeper with increased cutting time in the case of a flowrate of $0.02 \mathrm{~g} / \mathrm{s}$ at $0.427 \mathrm{MPa}$. Although it was anticipated that a longer drilling time can increase the hole depth, with the increase of the drilling time from $7 \mathrm{~s}$ to $10 \mathrm{~s}$ and finally to 15 s, no obvious changes or clear variation trends of the hole depth were observed. 
It has been assumed in previous literature, such as [6], that particles are congregated in the centre of the cross-section of the nozzle with a bell-shape type distribution inside a cylindrical nozzle. However, when the jet impacts on a target workpiece, due to the effects of flow bouncing back and stagnation, the particle distribution in the jet could be changed, especially under certain setup parameters such as in the cases afore discussed. It can be seen from Figs. 3-5 that, convex or W-shaped hole bottoms were obtained under low particle flow rate such as $0.02 \mathrm{~g} / \mathrm{s}$. It means that concentration of abrasive particles was shifted towards the brim rather than around the centre of the cross-section of the jet. It is evident that in comparison with the well-recognised particle distribution pattern in a free jet, there should be some variations on the distribution of the abrasive particles in the jet in the actual machining process in which a more complex flow dynamics exists. The flow bounce back and the stagnation effects can cause the distribution to become brim concentrated, or nearly evenly distributed, or centre concentrated distributions, depending on the abrasive particle flow rate, and the air pressure. An increase on particle flow rate will change the abrasive particle distribution in the jet, from brim concentrated to nearly evenly distributed, and then to centre concentrated. Such a trend can be demonstrated by the evolution of the measured hole profiles in Fig. 4. An increase of the air pressure may also change the abrasive particle distribution in the jet, in a similar trend as an increase of the particle flow rate.

During the AJM operation, the removal of target material is through erosion, which is realized by the mechanisms of micro-plastic deformation and/or brittle fracture. The plastic deformation and crack generation are caused by particle impact. Therefore, the kinetic energy of the abrasive jet is critical. For the materials such as glass which are brittle in nature and also hard, localised cracks at the work surface are formed due to the impact force of abrasive particles [1,11]. The formation and extension of the micro cracks with the succeeding impact of the abrasive particles are the main cause for the 
removal of the target material. The material removal rate is dependent on several process condition parameters, but primarily on the kinetic energy of impacting particles [21]. The particle velocity is undoubtedly the dominating process parameters in AJM [22]. It has been shown that the erosion efficiency grows with the kinetic energy of the abrasive jet which corresponds to the particle velocities [23]. The normal component of the impact energy from the abrasive particles to the work surface is believed to be the main source of the material erosion [24]. The erosion rate of materials and the resultant machined surface profile are thus influenced significantly by the impact velocity [25], the flow rate, and distribution of the abrasive particles. According to an investigation by Burwash et al. [26] on the deposition of particles by a confined impinging jet onto a flat surface, the particle deposition patterns were all circularly symmetric about the stagnation point and exhibited a ring-like form. The maximum deposition occurred furthest from the stagnation point when the nozzle-to-surface distance over the nozzle diameter (L/D) was around 2. Such a deposition pattern reflects the distribution of particles in an impinging jet, which affects the geometric shape of the hole bottom in AAJ hole drilling. The experimental results in this study agree to some extent with the deposition pattern reported in [26] with the occurrence of convex bottom shapes. It is noted that particle flow rate and air pressure level contribute significantly to the variation of the particle distribution pattern and thus the bottom shape. The smaller the particle flow rate, the more deposition occurs further from the stagnation point, therefore formation of convex bottom shapes is more likely. The increase of airjet pressure causes an enlargement of the stagnation area, which broadens the deposition of impinging particles within, thus forms the effective erosion zone outward to the impinging jet centre. A further study is needed to understand the phenomenon and to develop a reliable prediction model. 


\section{Conclusions}

In abrasive jet micromachining, the process parameters influence significantly the machined shape geometry, dimensional accuracy, surface integrity, and machining efficiency. The formation of micro-holes drilled using an abrasive airjet was investigated in this study. There are three types of surface contours obtained at the bottom of the holes, i.e., convex, flat and concave. The occurrence of different contour types are strongly affected by the magnitudes of airjet pressure and particle flow rate. It implies that a low particle flow rate causes more particle deposition further from the stagnation point and makes the formation of convex bottom shapes more likely. On the other hand, the enlargement of the stagnation area caused by an increase of airjet pressure broadens the deposition of impinging particles within, thus forming the effective erosion zone outward to the impinging jet centre. This effect is more pronounced with the number of particles enclosed within the jet. It was observed that an increase of machining time from $7 \mathrm{~s}$ to $15 \mathrm{~s}$ does not have a significant influence on the surface contours. The AJM technique is feasible in forming a micro-feature. By proper selection of airjet pressure and the particle flow rate, a desired feature can be fabricated.

\section{Acknowledgements}

The authors would like to acknowledge the contribution of Mr Ang Siang Foo and UNSW Australia in the experimental work.

\section{References}

[1].Li, H.Z., Wang, J., and Fan, J.M., Analysis and modeling of particle velocities in micro-abrasive air jet, International Journal of Machine Tools and Manufacture 2009. 49(11), 850-858. 
[2].Li, H.Z., Lee, A., Fan, J., Yeoh, G. H., \& Wang, J., On DEM-CFD Study of the Dynamic Characteristics of High Speed Micro Abrasive Air Jet. Powder Technology 2014. 267, 161-179.

[3].Li, H.Z., Process analysis of abrasive jet micromachining for brittle materials, Australian Journal of Mechanical Engineering 2012, 10(1), 61-70.

[4]. Momber, A., Blast Cleaning Technology, Springer-Verlag Berlin Heidelberg. ISBN: 978-3-540-73644-8. 2008.

[5]. Srikanth, D.V., SreenivasaRao, M., Metal Removal and Kerf Analysis in Abrasive Jet Drilling of Glass Sheets, Procedia Materials Science 2014, 6, pp. 1303-1311.

[6].Achtsnick, M., Geelhoed, P.F., Hoogstrate, A.M., Karpuschewski, B., Modelling and evaluation of the micro abrasive blasting process, Wear 2005, 259 (1-6), 84-94.

[7]. Balasubramaniam, R., Krishnan, J., Ramakrishnan, N., A study on the shape of the surface generated by abrasive jet machining, Journal of Materials Processing Technology 2002, 121(1), pp. 102-106.

[8]. Ghobeity, A., Ciampini, D., Papini, M., An analytical model of the effect of particle size distribution on the surface profile evolution in abrasive jet micromachining, Journal of Materials Processing Technology 2009, 209 (20), pp. 6067-6077.

[9]. Shafiei, N., Getu, H., Sadeghian, A., Papini, M., Computer simulation of developing abrasive jet machined profiles including particle interference, Journal of Materials Processing Technology 2009, 209 (9), pp. 4366-4378.

[10]. Burzynski, T., Papini, M., Analytical model of particle interference effects in divergent erosive jets, Tribology International 2010, 43 (3), 554-567. 
[11]. Li, Q.L., Wang J., and Huang, C.Z., Erosion mechanisms of monocrystalline silicon under a microparticle laden air jet, Journal of Applied Physics 2008, 104, 034903.

[12]. Ten Thije Boonkkamp, J.H.M., Jansen, J.K.M., An analytical solution for mechanical etching of glass by powder blasting, Journal of Engineering Mathematics 2002, 43, 385-399

[13]. Nouraei, H., Kowsari, K., Spelt, J.K., Papini, M., Surface evolution models for abrasive slurry jet micro-machining of channels and holes in glass, Wear 2014, 309(1-2), 65-73.

[14]. Haj Mohammad Jafar, R., Papini, M., and Spelt, J.K., Simulation of Erosive Smoothing in the Abrasive Jet Micro-machining of Glass, Journal of Materials Processing Technology 2013, 213, 2254-2261.

[15]. Jafar, R.H.M., Spelt, J.K., and Papini, M., Surface Roughness and Erosion Rate of Abrasive Jet Micro-machined Channels: Experiments and Analytical Model, Wear 2013, 303, 138-145.

[16]. Nouraei H, Wodoslawsky A, Papini M, Spelt JK. Characteristics of abrasive slurry jet micro-machining: A comparison with abrasive air jet micro-machining. J Mater Process Technol 2013;213:1711-24. doi:10.1016/j.jmatprotec.2013.03.024.

[17]. Wang J, Nguyen T, Pang KL. Mechanisms of microhole formation on glasses by an abrasive slurry jet. J Appl Phys 2009;105. doi:10.1063/1.3079802.

[18]. Mohammad RH, Nouraei H, Emamifar M, Papini M, Spelt JK. Erosion modeling in abrasive slurry jet micro-machining of brittle materials. J Manuf Process 2015;17:127-40. doi:10.1016/j.jmapro.2014.08.006. 
[19]. Nouraei H, Kowsari K, Samareh B, Spelt JK, Papini M. Calibrated CFD erosion modeling of abrasive slurry jet micro-machining of channels in ductile materials. J Manuf Process 2016;23:90-101. doi:10.1016/j.jmapro.2016.06.007.

[20]. Fan JM, Fan CM, Wang J. Flow Dynamic Simulation of Micro Abrasive Water Jet. Solid State Phenom 2011;175:171-6. doi:10.4028/www.scientific.net/SSP.175.171.

[21]. Ligthart, H.J., Slikkerveer, P.J., in’t Veld, F.H., Swinkels, P.H.W., Zonneveld, M.H., Glass and glass machining in Zeus panels, Philips Journal of Research 1996. 50(3/4), 475-499.

[22]. Khodke, P. M., Tidke, D. J., Ramarao, A. V., An Analytical Model for Material Removal in Abrasive Jet Machining for Brittle Materials. Materials and Manufacturing Processes 1996, 11 (4), 535-554.

[23]. Slikkerveer, P.J., Bouten, P.C.P., de Hass, F.C.M., High quality mechanical etching of brittle materials by powder blasting, Sensors and Actuators 2000, 85, 296-303.

[24]. Chiang, S.S., Marshall, D.B., Evans, A.G., The response of solids to elastic/plastic indentation. I. Stresses and residual stresses, Journal of Applied physics 1982, 53, 298-311.

[25]. Stevenson, A.N.J., Hutchings, M., Scaling laws for particle velocity in the gas-blast erosion test, Wear 1995, 181-183, 56-62.

[26]. Burwash, W., Finlay, W., \& Matida, E. Deposition of Particles by a Confined Impinging Jet onto a Flat Surface at Re $=10^{4}$, Aerosol Science and Technology, 2006; 40(3): 147-156, DOI: 10.1080/02786820500494551. 
Figures and Tables

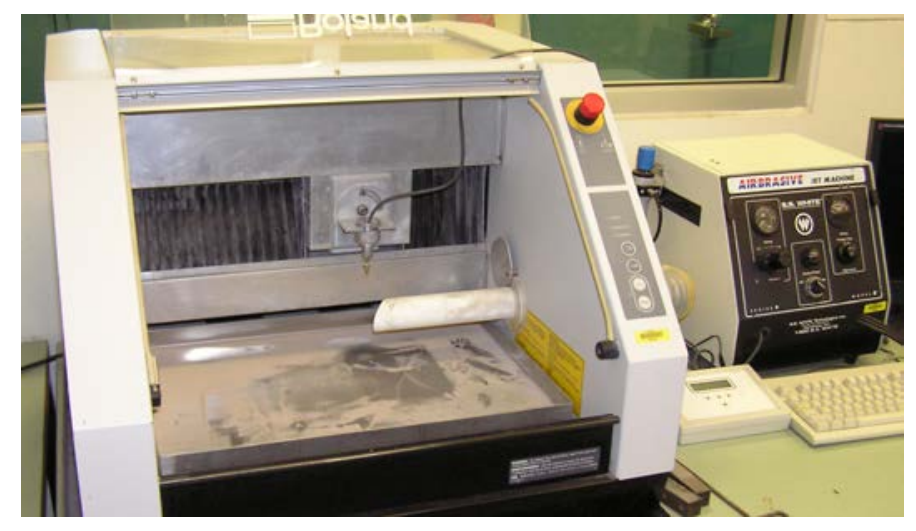

Figure 1. Experimental setup

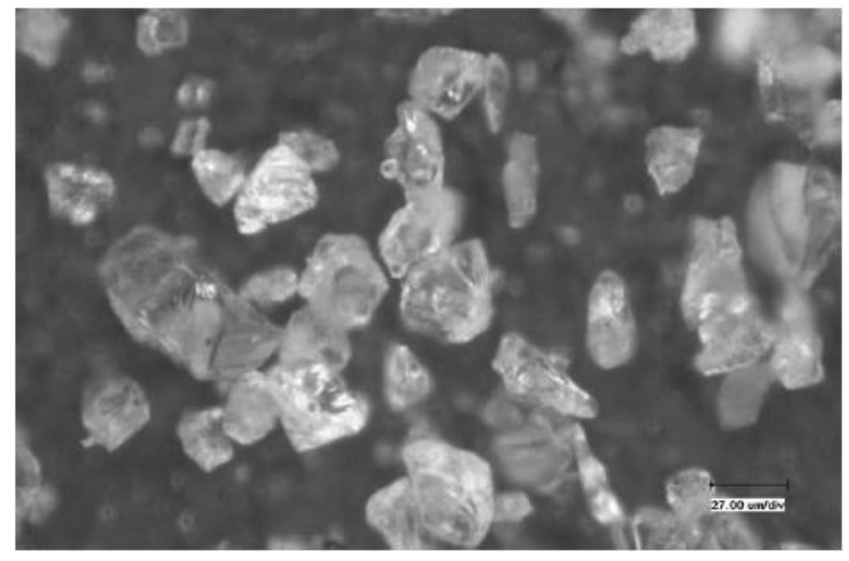

Figure 2. Image of the abrasive particles 
(a)
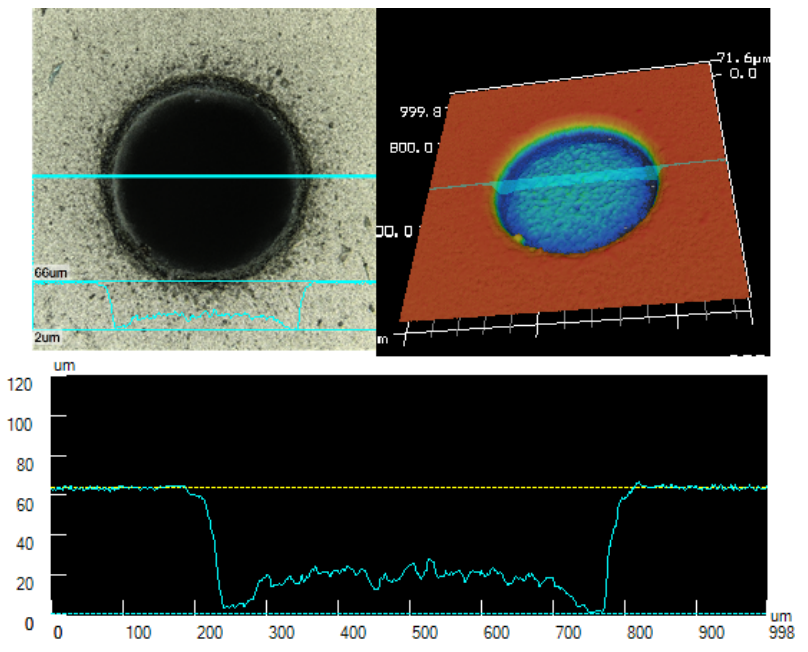

(b)
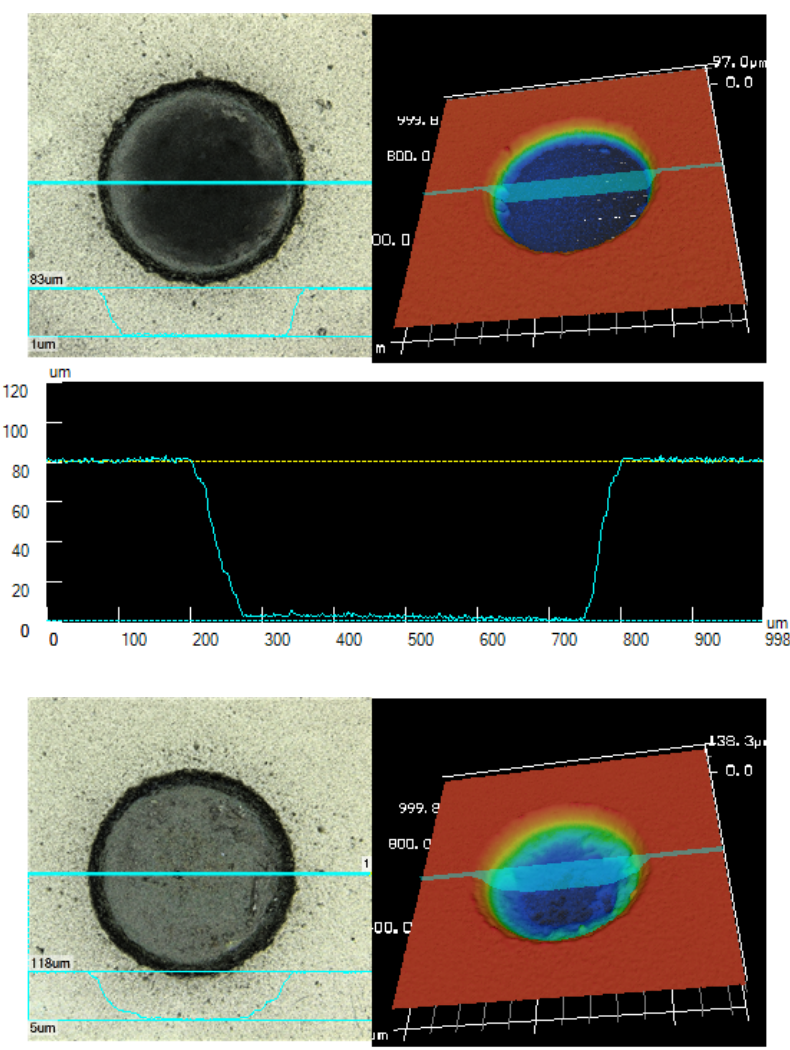

(c)

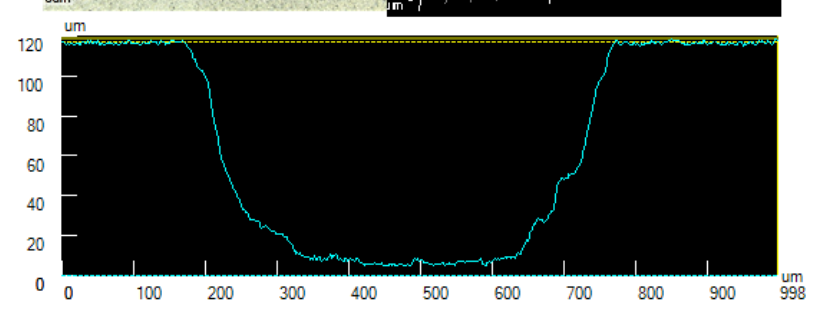

Figure 3. Three typical types of hole bottom contours fabricated on glass by AJM: (a) convex, (b) flat, and (c) concave. 

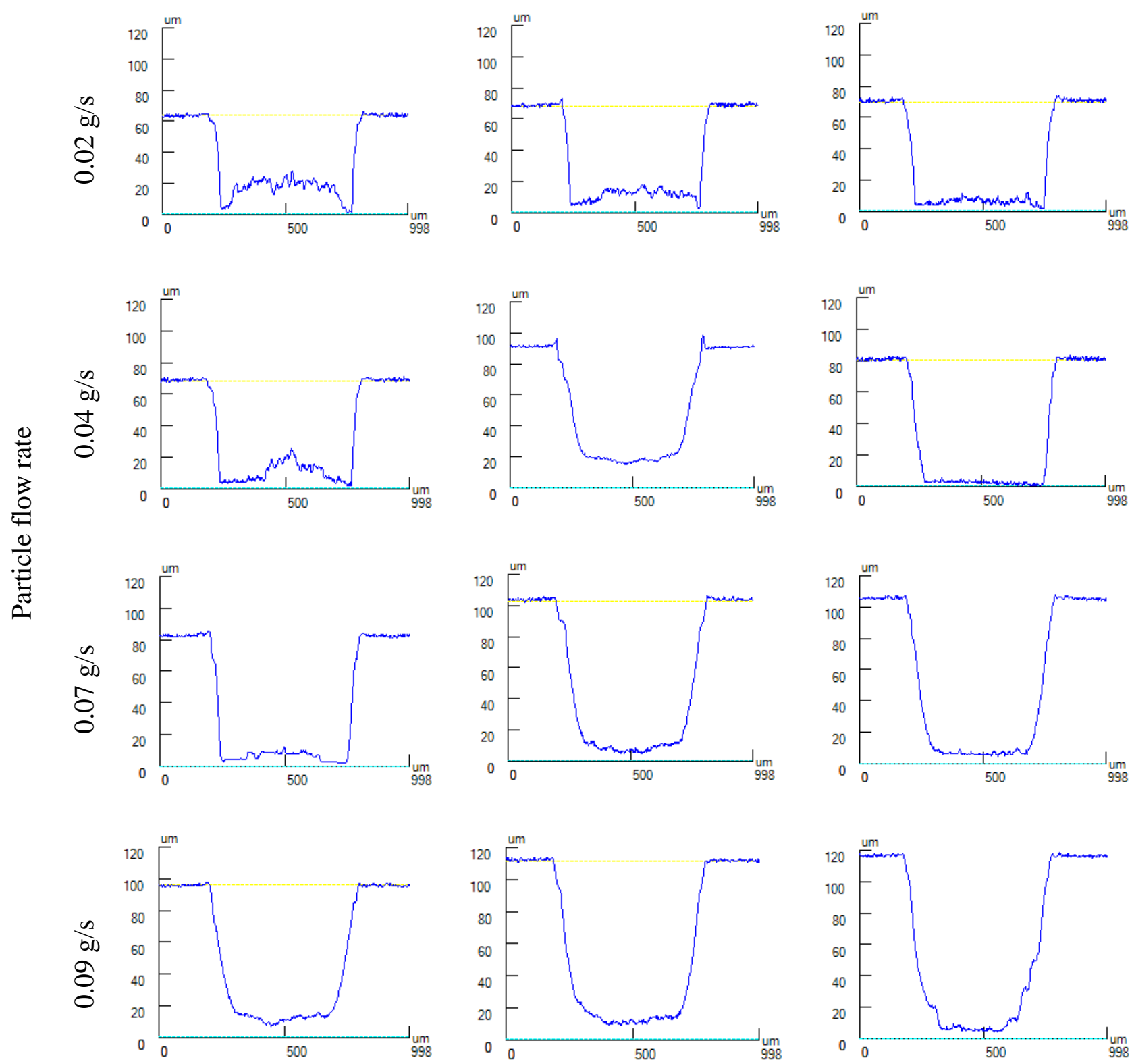

air pressure $0.427 \mathrm{MPa}$,
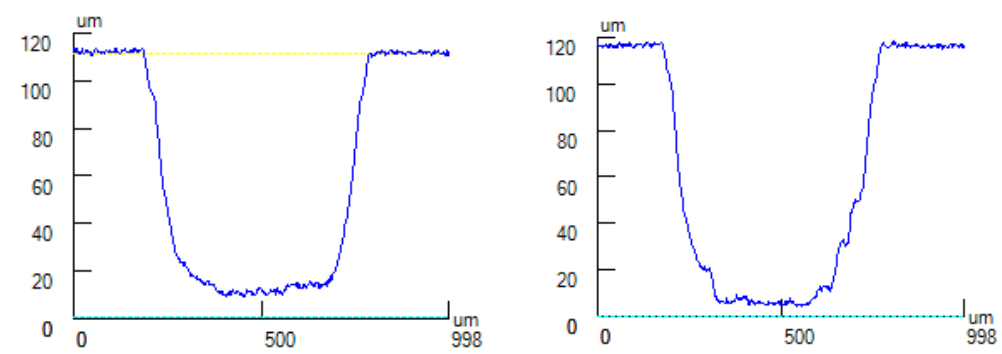

Figure 4. Comparison of the cross-sectional profiles of the micro holes fabricated by AJM on glass.

Cutting time $7 \mathrm{~s}$. Cutting condition: air pressure (from left column to right column) $0.427 \mathrm{MPa}, 0.517$ MPa, and 0.600 MPa ; abrasive particle flow rate (from top row to bottom row): $0.02 \mathrm{~g} / \mathrm{s} ; 0.04 \mathrm{~g} / \mathrm{s}$; $0.07 \mathrm{~g} / \mathrm{s}$; and $0.09 \mathrm{~g} / \mathrm{s}$. 

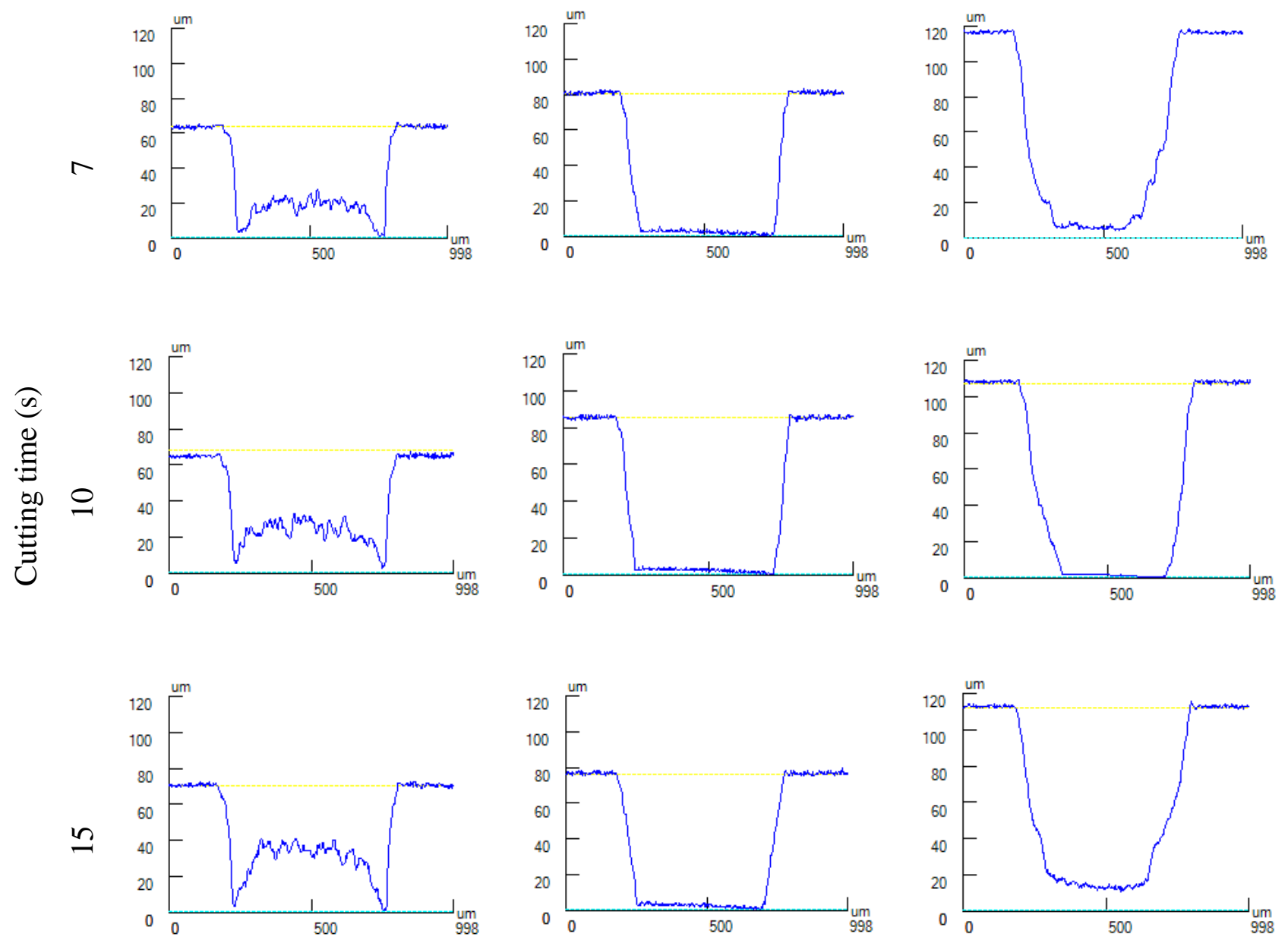

flow rate $0.02 \mathrm{~g} / \mathrm{s}$ air pressure $0.427 \mathrm{MPa}$

flow rate $0.04 \mathrm{~g} /$ air pressure $0.600 \mathrm{MPa} s$ flow rate $0.09 \mathrm{~g} / \mathrm{s}$ air pressure $0.600 \mathrm{MPa}$

Figure 5. Comparison of the cross-sectional profiles of the micro holes fabricated by AJM on glass.

Cutting time (from top row to bottom row): 7 s. 10 s, and 15 s; Cutting condition (from left column to right column): the abrasive particle flow rate $0.02 \mathrm{~g} / \mathrm{s}, 0.04 \mathrm{~g} / \mathrm{s}$, and $0.09 \mathrm{~g} / \mathrm{s}$, air pressure 0.427 MPa, 0.600 MPa, and 0.600 MPa. 